\title{
AN EXPLORATION ON PARENT'S GENDERED PERCEPTION
}

\author{
Samidha Dhungel Pokharel* \\ *Associate Professor, Department of Home Science, Padma Kanya Multiple Campus, \\ Kathmandu, TU
}

\begin{abstract}
Perception refers to the social knowledge which influences person's attitudes and behavior. Though the process of perception is similar, it differs from person to person depending upon the context. Based on the survey study conducted on Kathmandu Metropolitan city, this study explores the parental perception toward stereotypical thinking about sons and daughters. Furthermore, it also explores what factors in regards to religion, gender, ethnicity, education and income is more influential in shaping perception. The study was carried out during the year 2011 to 2013 with total of 269 respondents including father and mother having at least one son and daughter. Data were collected through a set of both structured and unstructured questions. Findings of the study suggest that stereotypical perception about boys and girls are deeply rooted in Nepalese society. Stereotypical perception toward boys is more rigid than girls. It has also been observed that perception is contextual and significantly influenced by gender, religion, ethnicity, education and economy. However educational status and economic condition are the major factors that influence shaping people's perception mostly. It can be concluded that bringing change in stereotypical perception is possible through improving peoples' educational status and income.
\end{abstract}

Keywords: gender roles - masculine and feminine traits - perception - educational status - income

\section{INTRODUCTION}

This paper is produced with the argument that perception is contextual and can be changed by creating appropriate environment. Perception, the social knowledge, is automatically activated in memory during the natural course. Such automatically activated information then 


\section{2}

AN EXPLORATION ON PARENT'S GENDERED PERCEPTION

guide people's judgment, attitude and behavior without being aware of such influence (Ferguson \& Bargh 2004). Though the process of perception is same to peoples, the content differs across the cultures that make individuals differing from one another. During the process of learning children become aware about the particular behaviors and attributes associated with sex; and develop their own gender schema (Bem 1981). Gender behavior and expectation between boys and girls become more vivid during puberty (Hallman \& Roca 2007). Adolescence is also known as second window of opportunity (UNICEF 2018). They are in the state of shaping long lasting gender beliefs and attitudes. So, early adolescence between the age of ten and fourteen is the most influential period to intervene before they solidify their ideas about gender norms (Lundgren, Beckman, Chaurasiya, Subhedi \& Kerner 2013).

Femininity/Masculinity, the culturally constructed perception toward male and female's characteristics is attached with various aspect of life such as human behavior, interest, emotions, social roles etc. Though, such perception is rooted profoundly in every society and differs from one community to another community, there are some general patterns. Traits like strong and weak; emotions such as aggressiveness and passiveness are considered masculine and feminine traits respectively. According to Margarete Mead (1935) (cited in Stet \& Burke 2000), these different emotions found in boys and girls are not because of biological differences, but due to the differences in socialization and cultural expectation held for each sex. According to "social role theory" two attributes communal and agentic are linked to femininity and masculinity. Based on such ascribed roles socialization of girls tends to be oriented towards affectionate, helpful, kind, sympathetic, interpersonally sensitive, nurturing and gentle. Unlike the girls, boys are socialized to be assertive, controlling, confident tendency such as aggressive, ambitious, dominant, forceful independent, self sufficient, and self confident (Eagly \& Karau 2002, Eagly, Wood, \& Diekman 2012).

Substantial studies done in Nepal disclose social perception as one of the prime factors associated with gendered practices. Gyanu Chhetri in her study entitled "Perception about the third gender in Nepal" argues that 
social norms and values contour an individual's perception and practice; and found parents and family exiling their own third gendered children from home because the fear of being detested by the society (Chhetri 2017). Gaurav et al. (2013) found gender as one of the major barrier to the treatment of Tuberculosis. Since male were considered as breadwinner, women prioritize their husband's health and reluctant to spend money on modern health services for themselves. Women rely on local medications or traditional beliefs secretly until the symptoms aggravate (Gaurav, Jha, Niraula, Yadav, Bhattarai \& Pokharel 2013). Social perception toward gender that "male is stronger than female" is one of the major causes of gender disparity which render social change and development in Nepal. Such belief is prevailed in all types of ethnic groups and identified need of further research to explore the corrective measure to address the socioculture causes of gender disparity (Shrestha \& Gartoulla 2015). This paper argue that it is imperative to figure out in what context in terms of ethnicity, religion, economy, gender and age is social perception deeply rooted for bringing changes in society. Such study is lacking in Nepalese context. This paper is focused in parental income, educational status, gender, ethnicity and religion; and its influence on gendered perception.

\section{METHODOLOGY}

Based on descriptive nature of the present study, it describes the prevalent stereotypical perception of parents toward sons and daughters. To get the diverse population (caste, religion, occupation, economy, education) Kathmandu metropolitan city where people from different family background and culture reside was purposively selected for the study. A total of 269 parents, from most of the wards, including father and mother having at least one son and one daughter, were approached through networking of the students studying Master Level in Home Science majoring Child Development and Gender Socialization; and friends and relatives. Once the respondents who met the inclusion criteria (family living with spouse, having at least one son and one daughter under the age of nineteen) identified were requested to give the address of similar types of other family they know for the purpose of data collection. 


\section{AN EXPLORATION ON PARENT'S GENDERED PERCEPTION}

Present study is based on primary data which were collected through interview with respondents. Because of the nature of the study a mixed method was used for the data collection. For the purpose of quantitative data, a set of structured questionnaire describing traditional sayings associated with sons and daughters in Nepalese family were produced in statement form and translated into English for the purpose of data interpretation. However, these questions were asked in Nepali during interview to make the research assistants and respondents understand the terms used in questionnaire easily. Parental perception toward sons and daughters were recorded in five point Likert scale and their expectations toward their sons and daughters about masculine and feminine behavior were collected through open ended questions. Parents were requested to list out their sons' and daughters' behaviors that they like and don't like. Data were collected from 2011 to last of 2013.

Quantitative data were entered in Statistical Package for Social Science (SPSS) and analyzed statistically. Mean, standard Deviation, and Chi-Square Test was computed in SPSS version 20 to analyze data. For this purpose ethnicity was categorized under three groups: caste group, Newar and hill ethnic group as (Gurung 2006). Caste-group includes majority of Hill Brahmin/Chhetri, and few Dalit and Terai Brahmin Chhetri. Similarly Hill-Ethnic group represent Gurung, Magar, Tamang, Sherpa, Rai and Limbu. Likewise educational group were categorized under 5 major groups illiterate, literate, basic educational group, high school to higher secondary level and BA and above. Similarly, the income of the respondents was categorized under three major groups: low middle and high according to their monthly income; and Hindu and Buddhist two religious groups. The narratives of parents were categorized under different themes and interpreted accordingly.

\section{RESULT}

\section{Parental gendered perception}

The findings of the study reveals that regardless to culture, ethnicity, gender, economy, age and educational level of the respondent people still perceive son and daughter stereo-typically. (Table 1) 
Table 1: Parental perception about son and daughter

\begin{tabular}{|c|c|c|c|c|c|c|}
\hline \multirow[b]{2}{*}{ Statements } & \multicolumn{6}{|c|}{ Percent } \\
\hline & $\begin{array}{l}\text { Strongly } \\
\text { disagree }\end{array}$ & Disagree & $\begin{array}{c}\text { No } \\
\text { opinion }\end{array}$ & Agree & $\begin{array}{c}\text { Strongly } \\
\text { Agree }\end{array}$ & $\begin{array}{c}\text { Mean } \\
\text { (std. } \\
\text { dev) }\end{array}$ \\
\hline $\begin{array}{l}\text { Daughter's prestige } \\
\text { is on the tip of } \\
\text { needle }\end{array}$ & 15.2 & 19.0 & 16.0 & 30.1 & 19.7 & $\begin{array}{c}3.20 \\
(1.362)\end{array}$ \\
\hline $\begin{array}{l}\text { Those who go to } \\
\text { other's home should } \\
\text { tolerate }\end{array}$ & 23.4 & 34.9 & 10.4 & 22.3 & 8.9 & $\begin{array}{c}2.58 \\
(1.304)\end{array}$ \\
\hline $\begin{array}{l}\text { No matter however } \\
\text { daughters study } \\
\text { should work on the } \\
\text { kitchen }\end{array}$ & 15.2 & 33.5 & 9.7 & 28.6 & 13.0 & $\begin{array}{c}2.91 \\
(1.322)\end{array}$ \\
\hline $\begin{array}{l}\text { Sons are the } \\
\text { supporter of parents } \\
\text { during old age }\end{array}$ & 11.2 & 22.7 & 22.3 & 33.5 & 10.4 & $\begin{array}{c}3.09 \\
(1.192)\end{array}$ \\
\hline $\begin{array}{l}\text { A man should take } \\
\text { responsibility of } \\
\text { wife and children }\end{array}$ & 11.2 & 14.1 & 19.3 & 42.0 & 13.4 & $\begin{array}{c}3.32 \\
(1.201)\end{array}$ \\
\hline $\begin{array}{l}\text { Should consider the } \\
\text { household advice of } \\
\text { a grown up son }\end{array}$ & 6.3 & 9.7 & 15.2 & 48.7 & 20.1 & $\begin{array}{c}3.67 \\
(1.096)\end{array}$ \\
\hline
\end{tabular}

A total of $68.8 \%$ think they should consider son's advice, $55.4 \%$ respondents believe a man should take care of their wife, 43.9\% consider son as supporter of old age. But when analyzing the statements attached with daughter, less than half of the respondents that is $49.8 \%$ respondents perceive daughters' prestige critically, $31.2 \%$ think daughters should have more tolerance capacity and $41.6 \%$ respondent think daughters should work in the kitchen. There was also significant number of respondents who had not any clear concept about gendered statements and expressed their opinion as no opinion.

\section{Gendered perception within different context}

A Chi-Square Test was computed to determine if gendered perception varies within religion, ethnicity, and gender of the respondents, education, income and age of the respondents. The findings of the study identified significant differences within different variables (Table 2). 
Table 2: Perceptional differences in religion, gender, ethnicity, education, income and age

\begin{tabular}{lcccccc}
\hline Statements & \multicolumn{5}{c}{ Assymp. Sig. (2-sided) } \\
& Religion & Gender & Ethnicity & Education & Income & Age \\
\hline $\begin{array}{l}\text { Daughter's prestige } \\
\text { is on the tip of } \\
\text { needle }\end{array}$ & 0.363 & $\mathbf{0 . 0 0 3}$ & 0.360 & $\mathbf{0 . 0 0 2}$ & $\mathbf{0 . 0 0 5}$ & 0.636 \\
$\begin{array}{l}\text { Those who go to } \\
\text { other's home should } \\
\text { tolerate }\end{array}$ & 0.612 & 0.135 & 0.633 & $\mathbf{0 . 0 0 0}$ & $\mathbf{0 . 0 0 0}$ & 0.170 \\
$\begin{array}{l}\text { No matter however } \\
\text { daughters study } \\
\text { should work on the } \\
\text { kitchen }\end{array}$ & 0.591 & $\mathbf{0 . 0 5 0}$ & 0.728 & $\mathbf{0 . 0 0 8}$ & $\mathbf{0 . 0 0 0}$ & 0.259 \\
$\begin{array}{l}\text { Sons are the } \\
\text { supporter of parents } \\
\text { during old age }\end{array}$ & 0.271 & 0.075 & 0.553 & $\mathbf{0 . 0 0 0}$ & 0.048 & 0.809 \\
$\begin{array}{l}\text { A man should take } \\
\text { responsibility of } \\
\text { wife and children }\end{array}$ & $\mathbf{0 . 0 3 8}$ & $\mathbf{0 . 0 1 3}$ & $\mathbf{0 . 0 2 4}$ & $\mathbf{0 . 0 0 5}$ & $\mathbf{0 . 0 3 9}$ & 0.323 \\
$\begin{array}{l}\text { Should consider the } \\
\text { household advice of } \\
\text { a grown up son }\end{array}$ & 0.545 & $\mathbf{0 . 0 0 3}$ & 0.922 & 0.350 & 0.338 & 0.909 \\
\hline
\end{tabular}

Religion: Significant differences between Hindu and Buddhist were observed about the son's responsibility taking role. More Buddhist than Hindu $(60.7 \%$ versus $51.3 \%$ respectively) perceived that a man should take responsibility of wife and children. The level of significant differences observed within religion was $\mathrm{p}=0.038$.

Gender: It was found that the perception of male and female about son and daughter differs significantly. More females than males were found to have stereotypical perception. Females perceive daughters' prestige as very fragile, believe daughters should work in kitchen at any cost, men should take responsibility of wife and children and should consider grown up son's advice. The significant differences observed in these statements was $\mathrm{p}=$ $0.003, p=0.050, p=0.013, p=0.003$ levels respectively.

Ethnicity: Hill ethnic group in comparison to Newar and Caste group had higher tendency of perceiving male as the bread winner of the family and 
their obligation to take care of family. The significant differences within ethnic group observed was at $\mathrm{p}=0.024$ level.

Age: The result of the study revealed the fact that age of the respondent has less influence on people's perception. There is no significant difference in perception within different age group ranging from 23 to 59. Majority of respondents either agreed or strongly agreed with the statements: son as supporter, sons' responsibility toward wife and children, involvement of son in household decision making. Unlike to son, majority of respondents either disagreed or strongly disagreed with the statements attached with daughters: daughters' tolerance qualities and obligation to kitchen work except daughters' prestige.

Education and income: The education and income level of the respondents were found to be highly influential in respondents' perception. These two variables influence all of the stereotypical perceptions attached with sons and daughters except son's involvement in household decision making. The differences observed was highly significant in almost all of the statements (see table 2). More respondents falling under low income group and educational status perceived stereotypically than those who fell under high income and educational status group. It was observed that as the education and income raise the stereotypical perception changes.

\section{Perceived masculinity and femininity traits}

Respondents were requested to express their views regarding masculinity and femininity by describing the masculine and feminine qualities they do not like in daughters and son respectively Parents were requested to think about their children's behavior which they do not like. Findings of the study show that influenced by traditional male dominated society, Nepalese family still continue traditional traits of masculinity and femininity. Parents are conscious about the son and daughters' volume of sound while talking; toys to play with; performing household chores; people son and daughter interact with; and also types of food son and daughter prefer to eat. During field visit, respondents described assertive, defiant, unemotional, frank, lazy, stubborn and leader qualities as masculine traits. On the other hand, elegant, obedient, emotional, shy, ease dropper, back biter, follower as feminine traits. During Field visit parents expressed their views on sexuality differently (Box 1). 


\section{Box 1. Sexuality as perceived by parents}

I do not like daughter's talking with loud voice and fighting like son (Father)

I do not like sons shedding tears on small matters (Father)

I do not like sons sitting on side and listening to people quietly and adding some comments time to time (Mother)

I do not like sons doing household chores for example washing clothes, cleaning utensils and sweeping floor (Mother)

I do not like daughters sitting idle they should be keeping doing something on (Mother)

I do not like sons playing with girlish toys (Mother)

I do not like son eating fatty, sour, hot food (chatpate) like girls (Father) I do not like daughters roaming around Community (village) like sons (Father)

I do not like daughters interacting, talking and mingling with many people (Mother).

\section{DISCUSSION}

In Nepalese society, different sayings related to prescribed and proscribed gender roles are very common and are being used enormously around the family, community and even at workplaces. People learn gender roles through verbal appellation and develop gender schema which guide their behavior. Once internalized, they transform such perception to next generation. Hence such statements not only influence perception but reconstructed again and again in every act of perception.

The findings suggest that the stereotypical perception attached to boys and girls is still deeply rooted in Nepalese society. If compared to boys and girls, such perception is more rigid to son than girls. Out of six stereotypical perceptions ( 3 to boys and 3 to girls) attached to boys and girls, majority of the respondents either agreed or strongly agreed with significant differences within different groups. The higher tendency of perceiving mandatory role of boys as breadwinner in Hill ethnic group in comparison to Caste and Newar Group, females in comparison to males 
and Buddhist in comparison to Hindu might be associated with their low educational background of the respondents that increases women's dependency on men. The present study is consistent with the study of Janet Morgan Riggs who found the evidence of societal expectation of father's role as breadwinner and mother's as care giver (Riggs, 1997). Girls are considered as prestige of the family which is associated with their virginity. Parents compare daughters with holy water which can be easily impure should be thrown away; and fragile glass which cannot be fixed once broken down. Such stereotypical perception toward girl's prestige is still persisting in traditional Nepalese society.

On the contrary, majority of the people have shown negative responses toward the perception related to daughter's tolerance ability, and kitchen as women's destiny. Gender is not fixed but a process (Butler, 2004 cited in Zizevskaia \& Shchukina 2018) it changes depending on context. The disagreement toward kitchen as the destiny of daughters might be the consequences of increased educational status and economic independency of women. Chi square test which have shown the higher the education and economic condition of an individual lowers the gendered perception attached to men and women in the society is also supported by Naila Kabeer who emphasizes women's education and employment to empower women and lessening gender inequalities in the society (Kabeer 2003, Kabeer 2005). Likewise, the changes in perception regarding tolerance qualities of daughter might be due to the awareness about women's right, discrimination and women empowerment. Present research finding is consistent with (Kane, 2006) who conducted qualitative study interviewing parents of preschool children and found that parents are liberal on gender nonconformity of their daughters but are not so in case of their son. Though parents accept some nonconforming tendencies on boys, they balance such nonconforming attitude with some efforts to approximate hegemonic ideas of masculinity. Parents including both father and mother, during field visit, expressed similar kind of anti- masculine and anti-feminine characteristics which they do not like was developing their daughters and sons respectively. Such hegemonic ideas influence people's attitude and behavior. This might be the reason why Pokharel (2018) found subtle discrimination in education. Even highly educated parents easily send their sons abroad for further studies. But when the turn comes to daughter they hesitate, use hook and crook and discourage to go abroad. Further studies in future about 
association between parental gendered perception and practices is needed to identify the degree of perceptional influence on gendered behavior.

A significant numbers of parent (9.7\% to $22.3 \%$ ) expressed as having no opinion about different sayings associated with gender expectation and gender roles of son and daughter. The reason of such response might be allied with the emerging trend of nuclear family, in and out migration of boys opting to grasp more opportunities and the media that highlights the social evils such as pushing parents out of the home, taking parents to the shelter home without their consent, and other troubles facing by parents because of their own sons; and daughters taking multi role like earning, taking care of parents during old age and lighting the pyre of parents if required. The finding of the study supports the argument that gendered perception is contextual and can be changed. Those who reported as no opinion in the gendered statements might be the more appropriate persons to change stereotypical gendered perception immediately from the society.

\section{CONCLUSION}

Different perception attached with boys and girls that create gendered behavior is still prevalent in Nepalese society. Majority of the parents perceive their son and daughter stereo-typically. Perceptions toward boys are more rigid in comparison to girls. Traits like assertive, defiant, unemotional, frank, lazy, stubborn and leader qualities as masculine, whereas elegant, obedient, emotional, shy, ease dropper, back biter, follower as feminine. However, such stereotypical perception is contextual. Amongst gender, religion, ethnicity, education and income; educational status and income of the parents are the most important factors that change their perception significantly. Bringing change in people's stereotypical perception is possible through increment in educational status and level of income. Peoples who have no clear opinion might be the more appropriate person to tap for the purpose of bringing change in gendered perception.

\section{REFERENCES}

Bem, S. L. (1981). Gender schema theory: A cognitive account of sex typing. Psychological Review, 88: 354-364.

Butler, J. (2004 ). Undoing gender. New York : Routledge .

Chhetri, G. (2017). Perceptions about the "Third Gender" in Nepal. Dhaulagiri Journal of Sociology and Anthropology, 11: 96-114. 
Eagly, A. H. \& Karau, S. J. (2002). Role: Congruity theory of prejudice toward female leader. Psychological Review, 109: 573-598.

Eagly, A. H., W. Wood \& Diekman, A. B. (2012). Social role theory of sex differences and similarities: A current appraisal. In: T. Eckes \& H. M.Trautner (eds.). The Developmental Social Psychology of Gender. NewYork: Psychology Press, pp. 123-174.

Ferguson, M. J. \& Bargh, J.A. (2004). How social perception can automatically influence behavior. Trends in Cognitive Sciences, $\mathbf{8}$ : 33-39.

Gaurav, K., Jha, N., Niraula, S., Yadav, D., Bhattarai, S. \& Pokharel, P. (2013). Gender based barriers in accessing tuberculosis. SAARC Journal of Tuberculosis, Lung Diseases \& HIV/AIDS, 10: 15-20.

Gurung, H. (2006). From Exclusion to Inclusion: Socio-political Agenda for Nepal. Lalitpur: Social Inclusion Research Fund p. 18

Hallman, K. \& Roca, E. (2007). Reducing the social exclusion of girls. http://www.popcouncil.org/uploads/pdfs/TABriefs/PGY_Brief27_ SocialExclusion.pdf (Accessed: 07.08.2012).

Kabeer, N. (2003). Gender equality in educational outcomes: A house hold perspective (Paper commissioned for the EFA Global Monitoring Report 2003/4, The Leap to Equality). http://unesdoc.unesco.org/ images/0014/001467/146781e.pdf (Accessed: 09.22.2017)

Kabeer, N. (2005). Gender equality and women's empowerment: A critical analysis of the third Millenium Development Goal 1. Gender Development, 13: 13-24.

Kane, E. W. (2006). No way my boys are going to be like that! Gender and Society, 20: 149-176.

Lundgren, R., Beckman, M., Chaurasiya, S. P., Subhedi, B. \& Kerner, B. (2013). Whose turn to do the dishes? Transforming gender attitudes and behaviours among very young adolescents in Nepal . Gender and Development, 21: 127-145.

Mead, M. (1935). Sex and temperament in three primitive societies. New York : Dell.

Pokharel, S.D. (2018). Subtle discrimination in education. The Journal of Association for Home Economics, 22: 33-39

Riggs, J. M. (1997). Mandates for mothers and fathers: Perceptions of bread winners and care givers. Sex Roles, 37: 565-580. 
Shrestha, A. \& Gartoulla, R. P. (2015). Socio-cultural causes of gender disparity in Nepalese society. Journal of Advanced Academic Research, 2: 100-111.

Stet, J. E. \& Burke, P. J. (2000). Femininity/masculinity. In: E. F. Borgatta, \& R. J. Montgomery (eds.) Encyclopedia of sociology. New York: Macmillan, pp. 997-1005.

UNICEF. (2018). Unicef programme guidance for the second decade: Programing with and for adolescents: https://www.unicef.org/ media/57336/file (Accessed: 31.12.2019).

Zizevskaia, E. \& Shchukina, M. (2018). Gender schemas in perception of gender-neutral images. Psychology in Russia: State of the Art, 11: 151-163. 